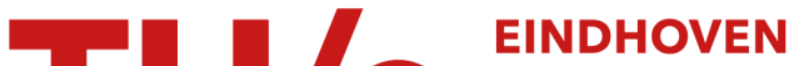 UNIVERSITY OF TECHNOLOGY
}

\section{The experimental setup of a large field operational test for cooperative driving vehicles at the $\mathrm{A} 270$}

\section{Citation for published version (APA):}

van den Broek, T. H. A., Netten, B. D., Hoedemaeker, M., \& Ploeg, J. (2012). The experimental setup of a large field operational test for cooperative driving vehicles at the A270. In Proceedings of the 13th International IEEE Conference on Intelligent Transportation Systems (ITSC 2010), 19-22 September 2010, Madeira Island, Portugal (pp. 198-203) https://doi.org/10.1109/ITSC.2010.5625050

DOI:

10.1109/ITSC. 2010.5625050

Document status and date:

Published: 01/01/2012

\section{Document Version:}

Publisher's PDF, also known as Version of Record (includes final page, issue and volume numbers)

\section{Please check the document version of this publication:}

- A submitted manuscript is the version of the article upon submission and before peer-review. There can be important differences between the submitted version and the official published version of record. People interested in the research are advised to contact the author for the final version of the publication, or visit the $\mathrm{DOI}$ to the publisher's website.

- The final author version and the galley proof are versions of the publication after peer review.

- The final published version features the final layout of the paper including the volume, issue and page numbers.

Link to publication

\section{General rights}

Copyright and moral rights for the publications made accessible in the public portal are retained by the authors and/or other copyright owners and it is a condition of accessing publications that users recognise and abide by the legal requirements associated with these rights.

- Users may download and print one copy of any publication from the public portal for the purpose of private study or research.

- You may not further distribute the material or use it for any profit-making activity or commercial gain

- You may freely distribute the URL identifying the publication in the public portal.

If the publication is distributed under the terms of Article 25fa of the Dutch Copyright Act, indicated by the "Taverne" license above, please follow below link for the End User Agreement:

www.tue.nl/taverne

Take down policy

If you believe that this document breaches copyright please contact us at:

openaccess@tue.nl

providing details and we will investigate your claim. 


\title{
The experimental setup of a large field operational test for cooperative driving vehicles at the A270
}

\author{
Thijs H.A. van den Broek, Bart D. Netten, Marika Hoedemaeker, and Jeroen Ploeg
}

\begin{abstract}
In this paper, a large field operational test (FOT) for cooperative driving systems, which take place on a public highway, is discussed. The experimental setup consist of a specific driver support system, which is closely related to cooperative adaptive cruise control (CACC) systems. Instead of autonomous vehicles, drivers are precisely advised how to accelerate or decelerate their vehicle. The location, A270 between Helmond and Eindhoven, is equipped with over 20 video cameras in order to monitor the performance of the equipped vehicles versus the non-equipped vehicles. The first results of this large-scale FOT are presented and discussed.
\end{abstract}

\section{INTRODUCTION}

$\mathrm{C}$ ONGESTION is a major societal problem in the Netherlands, considering a daily average total traffic jam length of over $200 \mathrm{~km}$ and peaks to well over $500 \mathrm{~km}$ during rush hours, whereas the country only measures $150 \times 300 \mathrm{~km}$ [1]. In order to significantly decrease the resulting vehicle loss hours (estimated at more than 40 million hours on a yearly basis), the Dutch government launched a policy that is directed towards an improved road use efficiency [2].

Traffic jams will obviously occur when the physical road capacity is not sufficiently high compared to the incoming traffic demand, for instance due to road works or accidents. Another major, essentially different phenomenon, leading to the occurrence of so-called ghost traffic jams, originates in the dynamic behavior of vehicles and their drivers when following each other at relatively close distances, common during rush hours. It can for instance be observed that a sudden, mild braking action of a single vehicle leads to a disturbance that amplifies in upstream direction, ultimately bringing the upstream vehicles to a full stop, without an apparent cause such as a road works. This phenomenon is elegantly recreated on a small scale in [3].

The underlying mechanism of ghost traffic jams is formalized by the notion of string stability, which states that

Manuscript received July 20, 2010. This work is supported in part by the Strategic Platform for Intelligent Traffic Systems (SPITS) project of SenterNovem, https://spits-project.com/.

Thijs H.A. van den Broek is with the Netherlands Organisation for Applied Scientific Research TNO, Integrated Safety - Automotive, Helmond, The Netherlands (corresponding author to provide phone: +3140 265-2688; fax: +3140-265-2601; e-mail: thijs.vandenbroek@tno.nl).

Bart Netten is with TNO, Computer Vision \& Statistics - Monitoring Systems, Delft, The Netherlands (e-mail: bart.netten@tno.nl).

Marika Hoedemaeker is with TNO, Traffic Behaviour - Human Factors, Soesterberg, The Netherlands (e-mail: marika.hoedemaeker@tno.nl).

Jeroen Ploeg is with TNO, Integrated Safety - Automotive, Helmond, The Netherlands (e-mail: jeroen.ploeg@tno.nl). a platoon ('string') of vehicles is stable when downstream disturbances are attenuated in upstream direction. As such, a string stable system contributes to a smooth traffic flow, which in turn leads to an efficient road use, less congestion and also to increased fuel efficiency [4]. From the experiment described in [3], it is apparent that human drivers generally exhibit string unstable behavior.

As opposed to human drivers, it might be expected that automatic systems, such as Adaptive Cruise Control (ACC), in principle could exhibit a significantly improved behavior in terms of string stability. To this end, the control design and analysis of automatic vehicle following systems is investigated extensively over the years, see e.g. [5],[6], leading to the development of Cooperative Adaptive Cruise Control (CACC), also referred to as (semi-) autonomous or intelligent cruise control. CACC can be regarded as common ACC, extended with wireless communication between vehicles to provide information about the motion of target vehicles that cannot be directly measured using on-board sensors, e.g. radar, lidar, vision, on the host vehicle. In [7], it is shown that ACC is only capable of achieving string stability at time gaps of about $2.8 \mathrm{~s}$ or higher, whereas CACC achieves string stability at time-gaps of $0.8 \mathrm{~s}$. Although these numbers depend on the communication structure, and on the vehicle and communication characteristics, they clearly illustrate the advantage of CACC over ACC since a small time gap, while retaining or achieving string stable behavior, directly contributes to an efficient road use.

Despite the apparent advantages of CACC, introduction in everyday traffic has yet to commence, the reason being that large-scale deployment is a very complex issue. It requires coordination and cooperation between automotive OEM's, communication parties and government, and, last but not least, sufficient public awareness.

In order to increase public awareness, a field test involving about 100 passenger vehicles has recently been executed on the A270 highway near Helmond in the east of the Netherlands. Since the instrumentation of such a large amount of vehicles with CACC is not feasible yet, a specific driver support system has been developed for this field test. The functionality of this system can best be characterized as an advisory form of CACC, providing the driver with acceleration information of multiple preceding vehicles.

This paper describes the set-up and the first results of this field test. To this end, Section II gives a short motivation for the choice of a driver-in-the-loop. Next, Section III describes the system architecture, and Section IV deals with the 
experimental setup. The methodological approach to analyze the measurement data resulting from the field tests is described in section V. Section VI then shows the first analysis results which are subsequently discussed in section VII. Finally, section VIII summarizes the main results by means of conclusions and recommendations.

\section{DRIVER-IN-THE-LOOP}

The purpose of the experiments on the A270 is to show the potential of cooperative systems on the improvement of mobility and the reduction of shockwaves in a traffic flow. Ideally these improvements are performed without the driver in the loop, i.e. the vehicle acts on its own. However, cooperative driving without the use of a driver might take another decade or more before it is launched on the market. Therefore, we have chosen that the driver has to respond to the desired accelerations. In this way the systems are close to market and realistic in the short term. With the driver-in-theloop concept, the output of the cooperative driving algorithm is presented to the driver by a human-machine interface (HMI). The design of this HMI is therefore a key issue in the success of the system. Note that for a good performance, the system is dependent on the reactions of the driver to this HMI.

\section{SySteM ARCHITECTURE}

Each vehicle is equipped with a cooperative driving system that determines the desired acceleration for the individual driver. The goal for the driver is to follow the desired acceleration advice as good as possible. The system architecture of the $i^{\text {th }}$-vehicle is described in Figure 1. Note that the $(i-1)^{\text {th }}$-vehicle is the direct predecessor of the $i^{\text {th }}$ vehicle.

Each vehicle contains the following hardware that is added to the vehicle:

1. Mobileye AWS-2000 camera [8];

2. TomTom GO 940 Live [9];

3. Gumstix [10], which consists of Overo Fire COM for wireless communication $(802.11 \mathrm{~b} / \mathrm{g})$ in combination with Chestnut 43 for USB and USB mini-B console;

4. WiFi antenna;

5. Kingston MicroSD of $2 \mathrm{~Gb}$.

The Mobileye AWS-2000 camera is used to determine the relative position and relative velocity of the predecessor. The TomTom is used for two reasons. First, it determines the absolute position, velocity and acceleration of its own vehicle. Second, the TomTom is the user interface to communicate the desired acceleration to the driver by means of vision and sound, i.e. the human-machine interface (HMI). The Gumstix is a computers-on-module product that creates a Linux embedded system. The IO of the Gumstix consists of USB, USB mini-B and WiFi. The range of the wireless communication is increased to roughly 250 meter by means of an external WiFi antenna. A Kingston MicroSD is added to the Gumstix that ensures that all data is logged locally. A controller is designed, which is based on [7]. The CACC

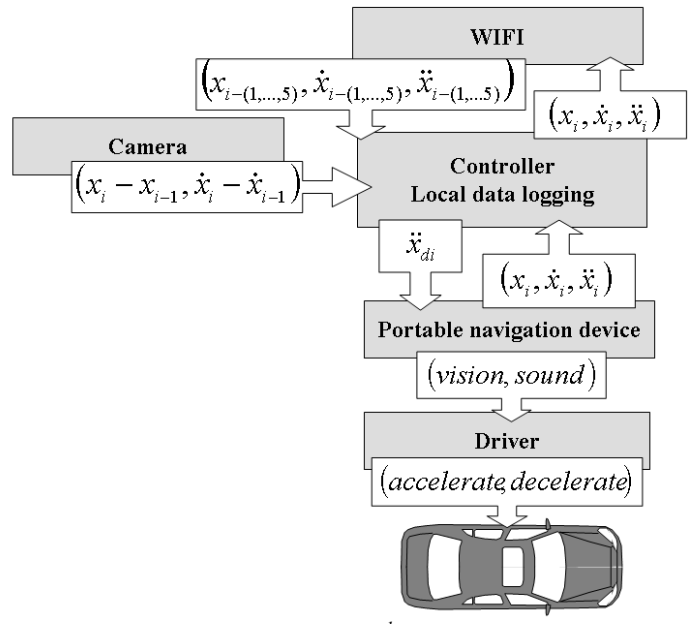

Fig. 1: System architecture of the $i^{\text {th }}$-vehicle.

controller of [7] is adjusted in order to deal with large time delays in the system. The large time delay in the system is mainly due to the driver who responds to the acceleration advice of the TomTom [11]. In [7] the feedforward is determined from the acceleration of only the direct predecessor. Here, we have chosen to determine the feedforward based on the acceleration of five predecessors. This new controller is analyzed in the frequency domain by mean of fast fourier transformation. With the use of the weak string stability criterion the difference between the controller of [7] and the newly designed controller based on five predecessors is compared. The weak string stability criterion deals with the amplification of accelerations upstream in the platoon. Here, it is desired to limit all amplifications of the acceleration as much as possible. For larger time delays, i.e. $\geq 0.4 \mathrm{~s}$, the new controller is more string stable compared to [7]. A time headway of $1.2 \mathrm{~s}$, in combination with a fixed distance at standstill of $2 \mathrm{~m}$, is chosen during the experiments.

\section{EXPERIMENTAL SETUP}

\section{A. Location}

A new test site is created as the location for this experiment. The A270 between Helmond and Eindhoven in the Netherlands is closed for these experiments, see Figure 2. The experiments take place on a public road to demonstrate to the general public that these types of experiments can take place at any given location. The highway is closed to avoid non-instructed drivers during the experiment.

\section{B. First vehicle}

The first vehicle is a vehicle of the organization. The first vehicle accelerates and decelerates at different locations and times to introduce shockwaves for the rest of the platoon. On February 21 and February 28, 2010, the following velocity variations are introduced by the first vehicle, see Table I. The accelerations vary per test. Some tests are repeated several times. The level of positive acceleration is limited, due to acceleration limitations of participant's vehicles. 


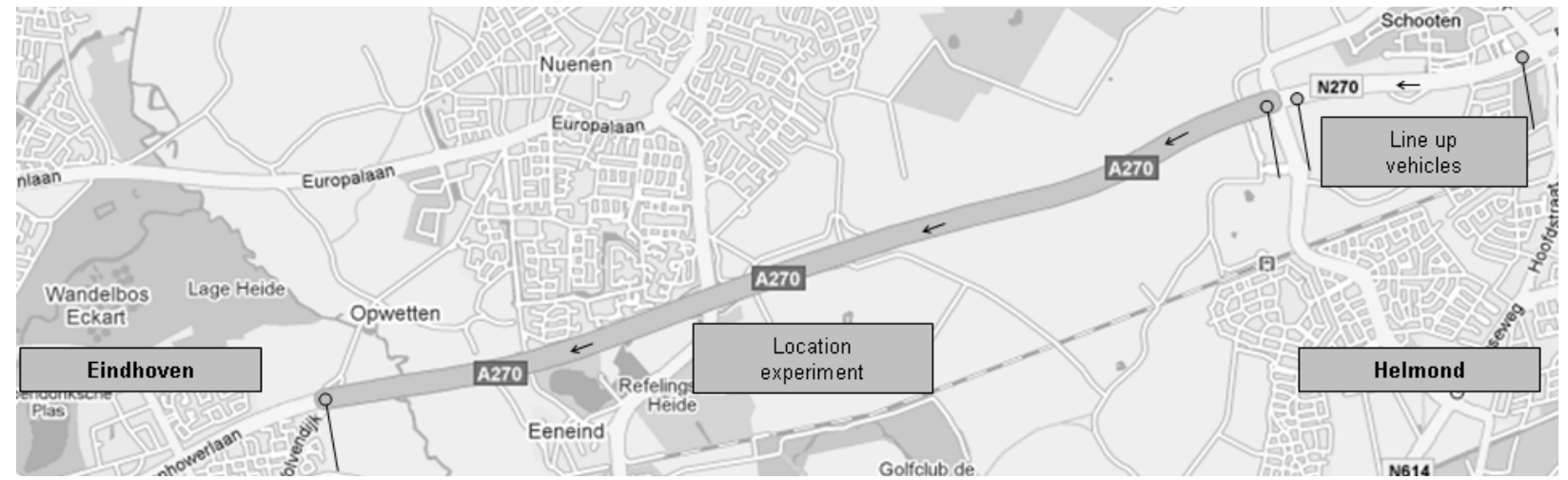

Fig. 2: Test location A270 between Helmond and Eindhoven (source: Google Maps).

TABLE I

VELOCITY VARIATIONS FIRST VEHICLE

\begin{tabular}{lll}
\hline \hline $\begin{array}{c}\text { Test } \\
\text { number }\end{array}$ & \multicolumn{1}{c}{ Velocity $[\mathrm{km} / \mathrm{h}]$} & \multicolumn{1}{c}{ Type of variation } \\
\hline 21.1 & $100-50-100-50$ & Sinusoidal \\
21.2 & $100-30(10 \mathrm{~s})-100$ & Step \\
21.3 & $100-30(10 \mathrm{~s})-100$ & Step \\
21.4 & $100-60-100-60$ & Sinusoidal \\
21.5 & $100-70-100-70$ & Sinusoidal \\
21.6 & $100-40-70-25(10 \mathrm{~s})-100$ & Step \\
28.1 & $100-70-100-50$ & Sinusoidal \\
28.2 & $100-50(10 \mathrm{~s})-100$ & Step \\
28.3 & $100-50-100-70$ & Sinusoidal \\
28.4 & 50 & Continuous \\
28.5 & $100-30(30 \mathrm{~s})-100$ & Step \\
28.6 & 100 & Continuous
\end{tabular}

\section{Number of vehicles}

In total 96 vehicles are used during the experiment on the A270 between Helmond and Eindhoven. The test vehicles are split in two groups with the same number of vehicles. The vehicles on the right lane are equipped with the cooperative system as described in Section III. Every fifth vehicle on the left lane is equipped with a data logger, which measures global position and velocity by means of GPS and measure acceleration by means of accelerometers. The other vehicles on the left lane are non-equipped. All participants are given clear instructions regarding their driving behavior. The driver instructions for the equipped lane are as follows:

1. You are on your way to work and you do not want to be late. It is crowded and you are in a hurry;

2. When you pass the first traffic light you will be on a crowded highway, where there are no traffic jams. The average speed is about $100 \mathrm{~km} / \mathrm{h}$;

3. Do not change lanes and you are not allowed to overtake predecessors;

4. Do not take into account the velocity of the vehicles in the other lane;

5. The cooperative system, which is installed in your vehicle, gives you advices how to accelerate or decelerate. Please follow the advice as good as possible;

6. You remain responsible that you do not collide with your predecessor.

The instructions for the drivers in the left lane, nonequipped vehicles, are very similar to the instruction of the equipped vehicles. Only the fifth instruction is different. The fifth instruction for the drivers of the non-equipped vehicles is:

5. Try to react as much as possible to your direct predecessor. Avoid large distances between your vehicle and your predecessor.

The vehicles are randomly chosen. During the test day the vehicles remain in the same position. Between test days the position of vehicles is changed.

\section{Human-machine interface}

To be able to chose a suitable way of communicating with the driver through a HMI in the A270 experiments, several HMI alternatives are tested by means of a driving simulator. The chosen HMI design consists of a triangle which fills up with red when (more) deceleration is needed or a circle which fills up with green when (more) acceleration is needed, see left and right plot of Figure 3, respectively.

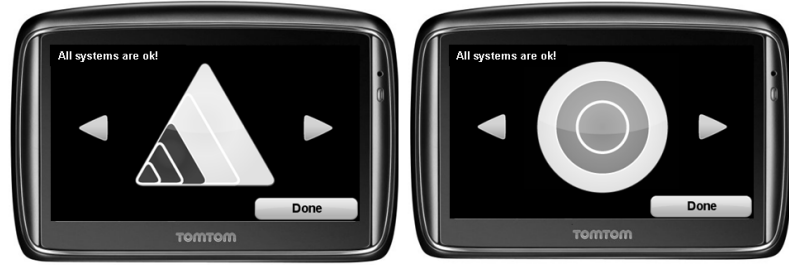

Fig. 3: HMI for deceleration (left) and acceleration (right)

The color signs are only shown when needed. As soon as no acceleration or deceleration is requested from the driver, i.e. a constant speed must be kept, the display is either a gray triangle or gray circle. When acceleration or deceleration gets more urgent an acoustic signal is added to the visual display saying "speed up" or "slow down", respectively. The reason behind the sound is that more attention is attracted to the needed action from the driver and it gives the driver an extra motivation to follow up the advice.

In the driving simulator tests, the cooperative driving algorithm received simulated input of an acceleration profile and position profile of 5 virtual preceding vehicles. Ten participants take part in the tests in which the participants drive with the design alternatives by following a lead car at $100 \mathrm{~km} / \mathrm{h}$ with a predefined speed profile. The driving simulator stores performance measures of each driver for analyses like speed, acceleration, time headway, time to 
collision, lane position. Each driver filled in a number of questionnaires on their acceptance and experience with the HMI.

Based on the results of the objective driving behavior data from the driving simulator and subjective questionnaire we have chosen to use zero green circles, one green circle, two green circles and three green circles of the right plot of Figure 3 for a desired acceleration of 0 to $0.5 \mathrm{~m} / \mathrm{s}^{2}, 0.5$ to 1 $\mathrm{m} / \mathrm{s}^{2}, 1$ to $1.5 \mathrm{~m} / \mathrm{s}^{2}$, and over $1.5 \mathrm{~m} / \mathrm{s}^{2}$, respectively. For the deceleration we have chosen zero red triangles, one red triangle, two red triangles, three red triangles, four red triangles and five red triangles of the left plot of Figure 3 for a desired deceleration of 0 to $-0.5 \mathrm{~m} / \mathrm{s}^{2},-0.5$ to

$-1 \mathrm{~m} / \mathrm{s}^{2},-1$ to $-1.5 \mathrm{~m} / \mathrm{s}^{2},-1.5$ to $-2 \mathrm{~m} / \mathrm{s}^{2},-2$ to $-2.5 \mathrm{~m} / \mathrm{s}^{2}$, and less than $-2.5 \mathrm{~m} / \mathrm{s}^{2}$, respectively.

\section{E. Decentralized data logging}

In Section III the system architecture is explained per vehicle. Data logging takes places on the Gumstix, see Figure 1. Here, the GPS position and GPS velocity, acceleration, relative position and relative velocity from the predecessor, received acceleration of other vehicles and desired acceleration are logged. First, the data is used to determine the performance of the individual system and driver. Second, the data is used to analyze the performance of the equipped vehicles versus the non-equipped vehicles. And finally, the data is used to validate the video-based monitoring (VBM) data.

\section{F. Centralized data logging}

On the right hand side of the highway 20 cameras are placed to record the driving actions of all vehicles, see Figure 4. The cameras are installed on $10 \mathrm{~m}$ high poles at a distance of one hundred meter, resulting in a total length of two kilometers, where both platoons are followed. The video image data is processed in such a fashion that it enables us to track each individual vehicle for the total length of two kilometers. Video-based monitoring [12] is used to extract vehicle trajectories, traffic and safety information, and shockwave patterns from the recorded footage.

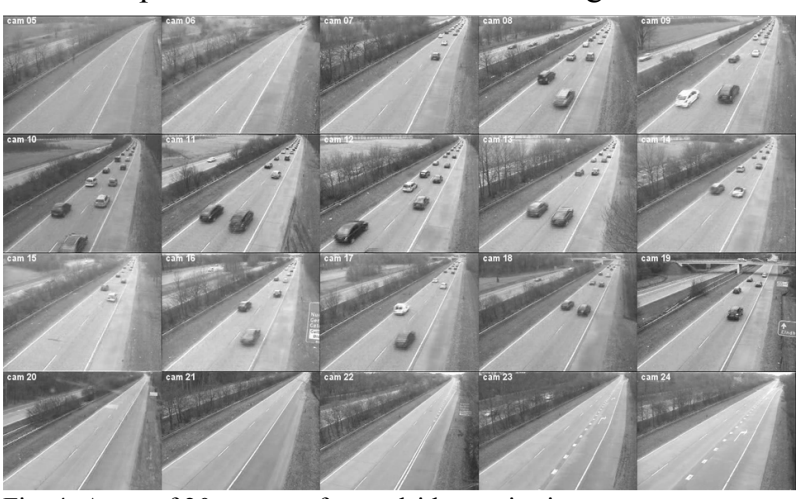

Fig. 4: Array of 20 cameras for roadside monitoring.

\section{DATA ANALYSIS}

In this section, experiment 21.3 is used to exemplify the data analysis. In all experiments one reference vehicle, with more accurate logging facilities, e.g. wheel speeds and a more accurate GPS, takes part in this experiment to validate the data from the on-board units and road side loggings. Figure 5 compares the velocity measurements of the reference vehicle with the on-board and road side measurements.

The measurements are filtered with a low pass filter afterwards, which ensures that there is no phase delay. Discrepancies in the order of $1 \mathrm{~m} / \mathrm{s}$ are observed between VBM and other measurement devices, which is adequate to measure and compare the shockwave behavior of equipped and non-equipped vehicles in the camera-covered area, see the solid black line in Figure 5.

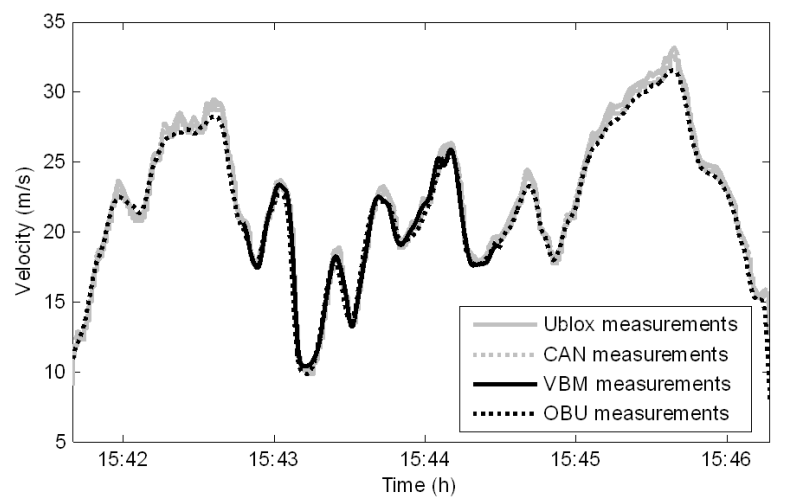

Fig. 5: Comparison from reference vehicle: on-board unit (OBU), road side unit (VBM), wheel speeds (CAN) and accurate GPS (Ublox).

Section II state that a good performance of the system depends on the reactions of the driver to the HMI. Here, we illustrate an example of the reactions of the driver of vehicle 38. The desired acceleration and the illustrations of the HMI corresponding with the desired acceleration, as defined in Section IV-D, are shown in Figure 6. The driver tries to follow the HMI advice as closely as possible. Nevertheless we observe a delay and overshoot in the final vehicle accelerations (solid black line). Larger deviations between HMI advice and vehicle accelerations have been observed for other vehicles.

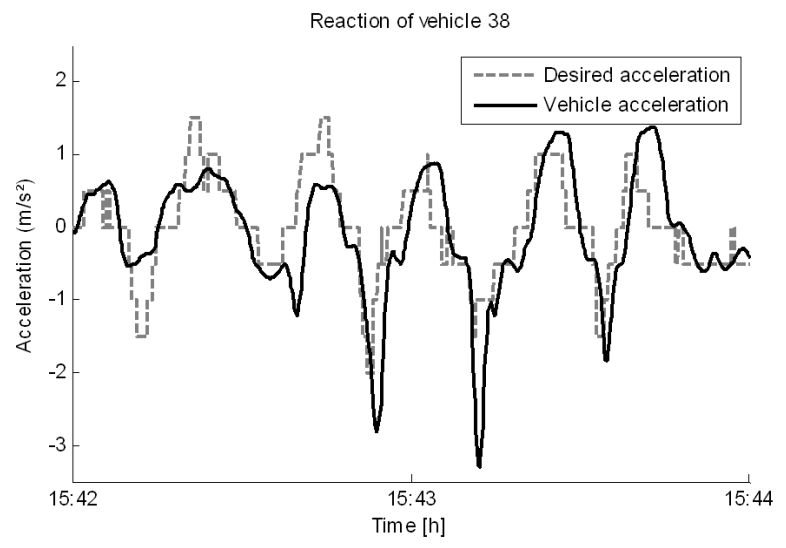

Fig. 6: Comparison of HMI input and driver reaction.

In Figure 7 the trajectories are shown for the lead vehicle and the $7^{\text {th }}, 17^{\text {th }}, 27^{\text {th }}, 37^{\text {th }}$, and $47^{\text {th }}$ equipped and nonequipped vehicle. The two brake actions from the lead vehicle result in shockwaves that run through both lanes. The 
drivers in the non-equipped vehicles, left plot of Figure 8, react in their usual way; they maintain their speed as long as possible before they have to brake as well. While decelerating, the non-equipped vehicles also tend to increase their time headways. This causes a shockwave of which the front travels with a speed of about $20 \mathrm{~km} / \mathrm{h}$ upstream.

Figure 7 shows that string length for the equipped vehicles is significantly smaller, and the maximum string length of the non-equipped vehicle is 6 vehicles, or $13 \%$, larger in this experiment.

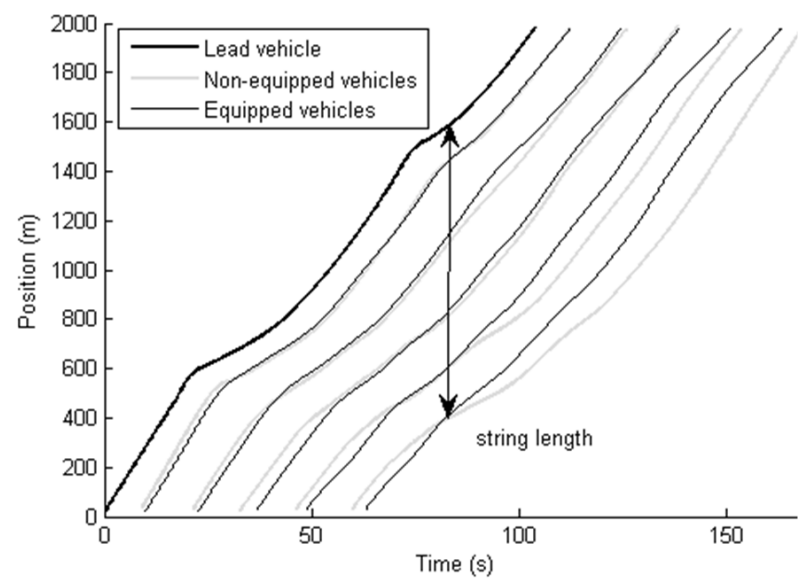

Fig. 7: Trajectories of the longitudinal position of the lead vehicle and the $7^{\text {th }}, 17^{\text {th }}, 27^{\text {th }}, 37^{\text {th }}$ and $47^{\text {th }}$ equipped and non-equipped vehicle over time.

The equipped vehicles communicate the deceleration upstream to inform the upstream vehicles. The early warning enables the equipped vehicles upstream to decelerate earlier and more gradually, and to maintaining a more constant headway time. This effect is illustrated in Figure 8 between the distance of 400 and $800 \mathrm{~m}$. Consequently, the shockwave becomes more or less stationary and less severe already after a few vehicles.
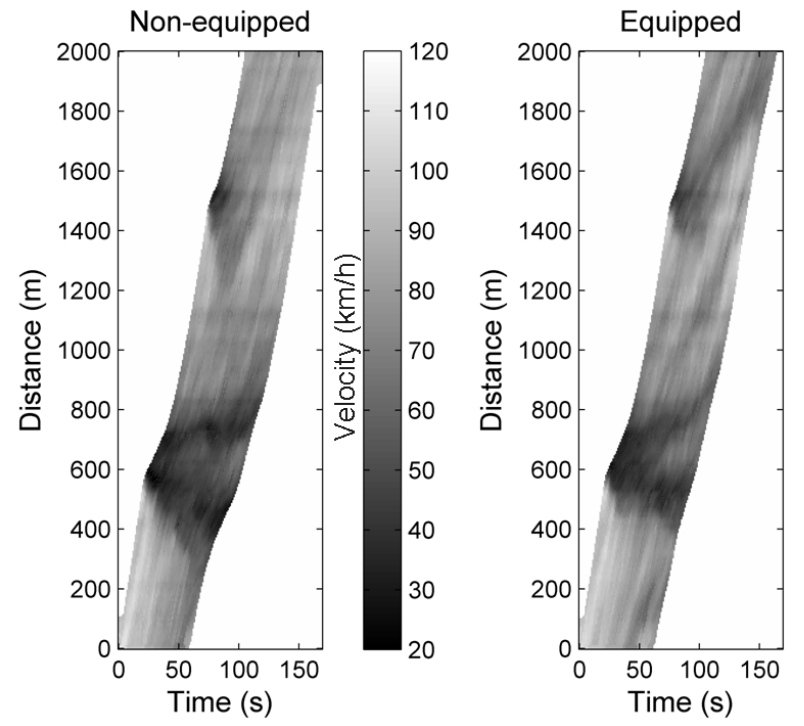

Fig. 8: Trajectories of the longitudinal position of the equipped and non-equipped vehicles over time. In the contour plots are the vehicle speeds shown for the non-equipped (left) and equipped (right) vehicles separately.
Also note some other shockwave phenomena. A second shock emerges as a bifurcation from the first brake action that travels downstream with a speed of about $7 \mathrm{~km} / \mathrm{h}$. The second brake action, which is around $1500 \mathrm{~m}$, is damped faster by the non-equipped vehicles primarily due to the larger headways resulting from the first shock. These phenomena need to be investigated in more detail.

Traffic efficiency can be evaluated in terms of traffic flow and density. Since traffic flow is determined by the speed of the lead vehicle in these experiments, flow is not discriminative. The density, on the other hand, varies significantly through shockwaves. If the string of vehicles is considered as an excerpt from a traffic stream, density can be determined from the string length during the experiments. Obviously, string length will shorten while driving into a shock, and extend while accelerating out of a shock.

\section{FIRST RESULT}

The series of field experiments provide a first indication of the traffic efficiency improvement that could be obtained with the advisory CACC system. Figure 9 shows the average speeds versus average densities for all experiments.

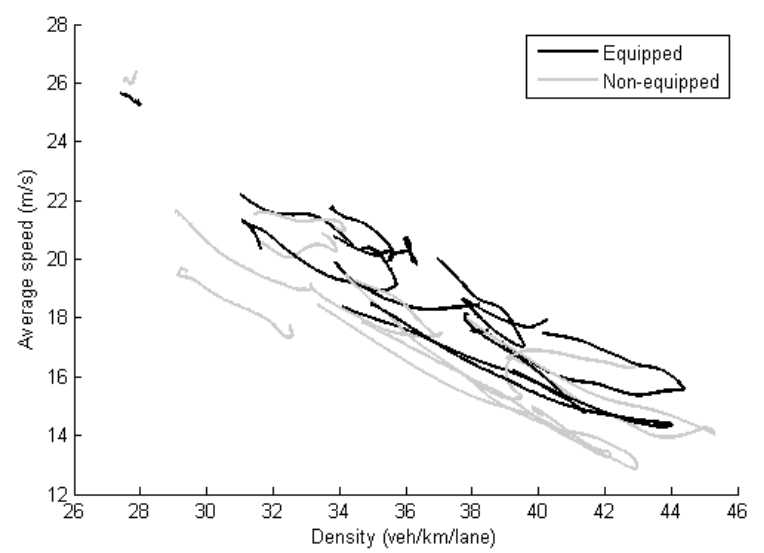

Fig. 9: Average speed and average density over all experiments.

Each line in Figure 9 represents the congested traffic situation in a single experiment. As a reference, one experiment is analyzed with a constant velocity. Here, the average velocity is about $26 \mathrm{~m} / \mathrm{s}$ and the density is about 28 vehicles/km/lane. Note that the average speed of this experiment is higher for the non-equipped vehicles, e.g. the drivers of the non-equipped vehicles drive with a time headway smaller than $1.2 \mathrm{~s}$, see Figure 9. In general, Figure 9 shows that the advisory system increases the traffic density by several vehicles per $\mathrm{km}$ per lane, at comparable speeds, across the executed range of congested traffic situations. Occasionally the non-equipped vehicles approach the performance of the equipped vehicles as a consequence of the variations in driver behavior rather than the advisory system.

The effect on traffic density can be explained from the support provided by the advisory system to reduce the variations in time headways maintained by the drivers, see Figure 10. The unassisted driver accepts smaller headways 
during braking and larger headways during the acceleration after the downstream shockwave.

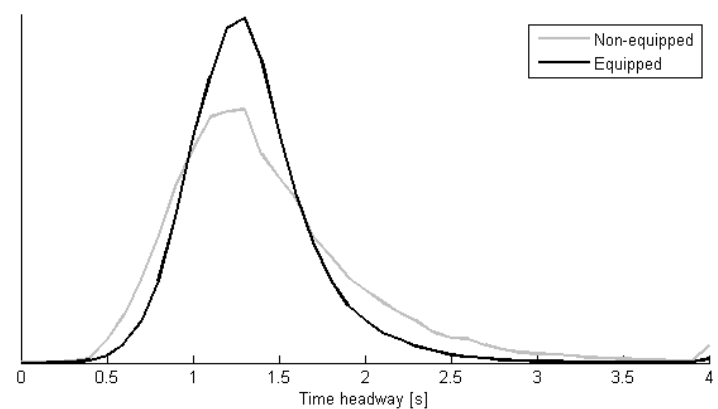

Fig. 10: Histogram of time headway over all experiments.

\section{DISCUSSION}

It is necessary to experiment several days to gather sufficient information for conclusive results. Differences between experiments are noticeable, since we have driversin-the-loop. It is obviously a major challenge to ensure that all drivers perform as best as possible. Therefore, we have chosen to test with this system for three days. Drivers are able to learn from the system. Secondly, the system of Section III is tweaked to the driver's desires.

The group of equipped vehicles had a larger average density with similar average velocities, see Figure 9. Though, the benefit differs per experiment due to three reasons. First, some drivers are able to follow the desired acceleration very accurate, while some drivers have large offsets and/or time delays while following the desired acceleration. Second, during February 28 the weather changed drastically. Lots of rain and strong winds change driver behavior enormously. And finally, the disturbance of the first vehicle influences the performance as well.

\section{CONCLUSION}

In this paper the experimental set-up and first results of a large field operational test for cooperative driving systems is explained, which raises public awareness to prevent and damp so-called ghost traffic jams with the use of cooperative driving technology. The first results shown in this paper illustrates that for almost all experiments the density of the group of equipped vehicles is higher with a similar average speeds, i.e. the throughput for the equipped vehicles is larger compared to non-equipped vehicles. Secondly, the velocity variations are lower for the equipped vehicles compared to the non-equipped vehicles. The total benefit with respect to throughput varies between experiments, due external effects, e.g. drivers, weather. Determining the main reason(s) for the benefit differences between experiments is still ongoing work.

Currently, the implementation of these cooperative driving technologies in everyday traffic takes place in two paths. First, testing actual CACC in a large field operational test. Second, showing the potential of cooperative driving technologies with mixed traffic. The main goal of experiments with mixed traffic is to show the benefit of these technologies with low penetration numbers. Solutions are created which combine roadside units with real-time videobased monitoring to monitor shockwave behavior of all vehicles and to inform CACC vehicles far ahead of their own communication range.

\section{REFERENCES}

[1] The Royal Dutch Touring Club ANWB, Stijging filezwaarte zet door, 2010, http://www.anwb.nl/verkeer/nieuws-en-tips/archief,/nederland/ 2010/juni/Stijging-filezwaarte-zet-door.html (in Dutch)

[2] Ministry of Transport, Public Works and Water Management, Nota Mobiliteit; Naar een betrouwbare en voorspelbare bereikbaarheid. The Hague, 2004 (in Dutch)

[3] Sugiyama, Y., et al. Traffic Jams without Bottlenecks - Experimental Evidence for the Physical Mechanism of the Formation of a Jam, New Journal of Physics, Vol. 10 (033001), No. 7, 2008

[4] Arem, B. van, C. J. G. van Driel, and R. Visser, The Impact of Cooperative Adaptive Cruise Control on Traffic-Flow Characteristics, IEEE Transactions on Intelligent Transportation Systems, Vol. 7. No. 4, pp. 429-436, 2006

[5] Barbieri, E., Stability Analysis of a Class of Interconnected Systems, ASME Journal of Dynamic Systems, Measurement, and Control, Vol. 115 , No. 3, pp. 546-551, 1993

[6] Swaroop, D., and J. K. Hedrick, String Stability of Interconnected Systems, IEEE Transactions on Automatic Control, Vol. 41, No. 3, pp. 349-357, 1996

[7] Naus, G. J. L., R. Vugts, J. Ploeg, R. van de Molengraft and M. Steinbuch, Towards On-the-road Implementation of Cooperative Adaptive Cruise Control. Proceedings of the $16^{\text {th }}$ World Congress \& Exhibition on Intelligent Transport Systems and Services (ITS World 2009), Stockholm, Sweden, September 21-25, 2009

[8] Mobileye Technologies Ltd., Mobileye AWS-2000 User Manual, 2008. Available: www.mobileye.com

[9] TomTom International BV, TomTom GO 940/740/540 LIVE Reference Guide, 2008. Available: www.tomtom.com

[10] www.gumstix.com

[11] Wickens, C.D., J.D. Lee, Y. Liu, S.E. Gordon Becker, An introduction to Human Factor Engineering, $2^{\text {nd }}$ ed. New Jersey: Pearson Eduction, Inc, 2004.

[12] Van Huis, J., Baan, J., van Loon, A., Traffic Monitoring using videobased vehicle tracking, ITS Stockholm, 2009 